\title{
Airway foreign body in a premature newborn
}

\author{
Alexander Trujillo, MD \\ Received: 24 April 2020/Revised: 18 May 2020/Accepted: 19 May 2020/Published online: 2 June 2020
}

(C) Canadian Anesthesiologists' Society 2020

A 28-week, 1130-g premature newborn was referred to our hospital after requiring orotracheal intubation and surfactant administration. The chest radiograph on admission showed a foreign body (FB) in the right bronchus (Figure A). The initial hospital reported having had no complications during orotracheal intubation. The patient's stable condition allowed a chest computed tomography scan to be performed to clarify the diagnosis, and measure the distance from the glottis to the proximal end of the $\mathrm{FB}(13 \mathrm{~mm})$ and the narrowest diameter of the glottis $(3.3 \mathrm{~mm})$. As our rigid bronchoscope was too large for the patient's airway, we planned to use a 9.5 Fr (3.17 mm) rigid video-uretocystoscope (VUS) to assist in FB removal using grasping forceps through its working channel. The patient was premedicated with atropine and inhaled anesthesia was administered with sevoflurane and oxygen while maintaining spontaneous respiration with a face mask. The side port of the VUS was used for oxygen administration $\left(1 \mathrm{~L} \cdot \mathrm{min}^{-1}\right)$ with clinical monitoring of exhalation to avoid barotrauma. The FB was removed on the first attempt without complications (see eVideo in the Electronic Supplementary Material) and on further inspection, was revealed to be the plastic sheath of an endotracheal intubation stylet (Figure B).

Endobronchial FB retrieval in a premature baby represents a serious challenge for surgical team members who are sharing the airway management. There are several different airway instruments that can be used. ${ }^{1,2}$ When an

Electronic supplementary material The online version of this article (https://doi.org/10.1007/s12630-020-01724-2) contains supplementary material, which is available to authorized users.

A. Trujillo, MD (ه)

Programa de Medicina, Universidad de Manizales, Manizales, Colombia

e-mail: alextrume@gmail.com

Facultad de Ciencias para la Salud, Universidad de Caldas, Manizales, Colombia 
Figure A) Anteroposterior chest radiograph showing a long radiopaque foreign body in the right mainstem bronchus (arrows) and partial atelectasis of the right upper lobe. B) A 5$\mathrm{cm}$ segment of plastic tubing, subsequently identified as a fragment of the plastic sheath of the endotracheal intubation stylet, that was removed from the patient. An undamaged intubation stylet is shown for comparison.
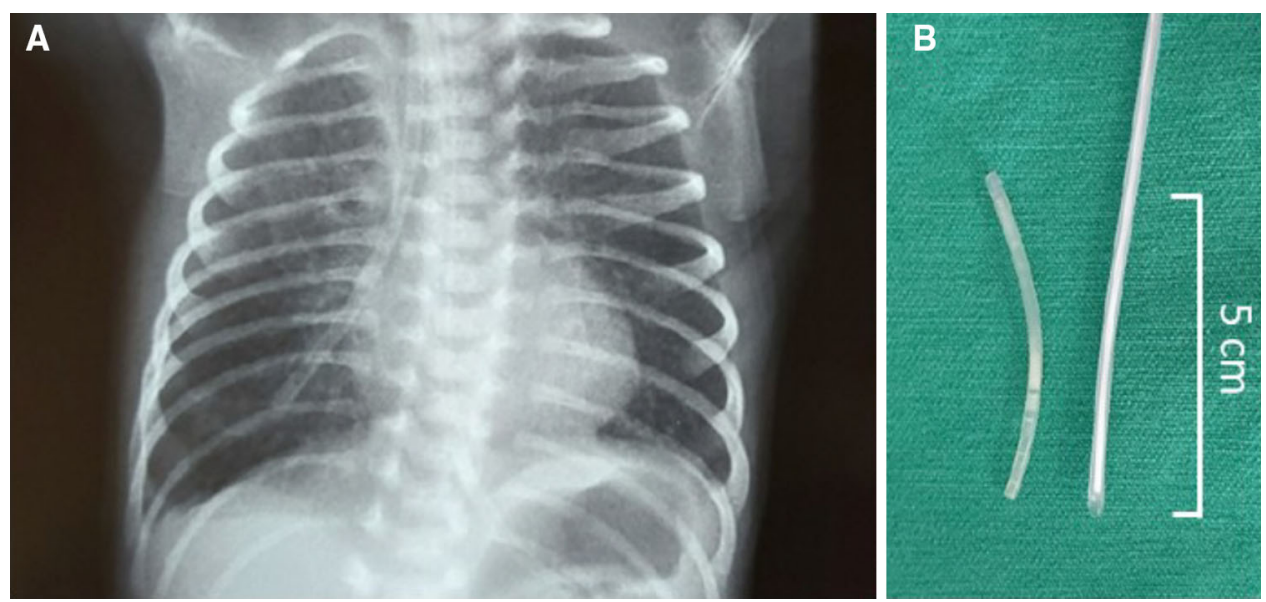

appropriately sized rigid bronchoscope is not available, the use of a VUS might be considered, coupled with appropriate preoperative planning and imaging, to reduce removal attempts, airway trauma, and the potential risk of complications.

Disclosures None.

\section{Funding statement None.}

Editorial responsibility This submission was handled by Dr. Hilary P. Grocott, Editor-in-Chief, Canadian Journal of Anesthesia.

\section{References}

1. Jasinovic T, Thamboo A, Osiovich H, Scheepers L, Robinson A, Ludemann JP. Best management of ultra-small tracheobronchial foreign bodies in neonates. Int J Pediatr Otorhinolaryngol 2013; 77: 434-8.

2. Fidkowski $C W$, Zheng H, Firth PG. The anesthetic considerations of tracheobronchial foreign bodies in children: a literature review of 12,979 cases. Anesth Analg 2010; 111: 1016-25.

Publisher's Note Springer Nature remains neutral with regard to jurisdictional claims in published maps and institutional affiliations. 